Article

\title{
Dynamics of Bacterial Community Diversity and Structure in the Terminal Reservoir of the South-To-North Water Diversion Project in China
}

\author{
Jiangqi Qu $\left.{ }^{1}{ }^{(}\right)$, Chengxia Jia ${ }^{1}$, Qing Liu ${ }^{2}$, Zhi Li ${ }^{1,2}$, Pan Liu ${ }^{1}$, Mu Yang ${ }^{1}$, Meng Zhao ${ }^{1}$, \\ Wentong $\mathrm{Li}^{1}{ }^{1}$, Hua Zhu ${ }^{1}$ and Qingjing Zhang ${ }^{1, *}$ \\ 1 Beijing Key Laboratory of Fishery Biotechnology, Beijing Fisheries Research Institute, Beijing 100068, China; \\ quqi20122012@163.com (J.Q.); Jia.cx@163.com (C.J.); Lizhi@bjfishery.com (Z.L.); liupan@bjfishery.com (P.L.); \\ yangmu@bjfishery.com (M.Y.); zhaomeng@bjfishery.com (M.Z.); liwentong@bjfishery.com (W.L.); \\ zhuhua@bjfishery.com (H.Z.) \\ 2 Key Laboratory of Hydrobiology of Liaoning Province, Dalian Ocean University, Dalian 116023, China; \\ liuqing@dlou.edu.cn \\ * Correspondence: zhangqjhbs@126.com; Tel.: +86-010-6758-8901
}

Received: 27 April 2018; Accepted: 25 May 2018; Published: 31 May 2018

\begin{abstract}
The South-to-North Water Diversion Project (SNWDP) is the largest water transfer project in the world, and its purpose is to relax water constraints in a region facing severe water scarcity. Bacterial communities from these reservoirs are important to human health, and analyzing their diversity and structure is crucial to water safety. Here, we investigated the dynamics of bacterial communities and their relationship with environmental parameters in the terminal reservoir (Miyun Reservoir) of the Middle Route of the SNWDP by high-throughput sequencing technology. Our results showed that Firmicutes, Proteobacteria, Cyanobacteria and Bacterioidetes were the most abundant phyla in the water column, and the community composition fluctuated seasonally. Moreover, the detected diversity of the bacterial community composition provided novel insights into the ongoing biogeochemical processes. The temperature was positively correlated with the dominant bacteria, with other factors, including the total dissolved solids, total phosphorus, dissolved oxygen and total nitrogen, shaping the structure and distribution of the microbial community. Furthermore, the metagenome showed broad phylogenetic diversity, indicating that organisms were involved in multiple essential environmental processes. This work is important for building a database to understand how microbial communities change after water transfers.
\end{abstract}

Keywords: bacterial community; diversity and structure; terminal reservoir; South-to-North Water Diversion

\section{Introduction}

Reservoirs for water supply purposes are highly regulated in China. As complex artificial ecosystems, they may have artificial or natural cycles (depending on replenishments and withdrawals) as well as high spatial and temporal heterogeneity [1,2]. Such changes can have profound impacts on the compositions of prokaryotic communities and other organisms [3-5]. The composition of bacterioplankton communities in aquatic ecosystems can be highly diverse in response to both spatial-temporal environmental variations and anthropogenic activities, and changes in composition may influence drinking water quality and surrounding biodiversity. Moreover, knowledge of bacterioplankton diversity and time-site distribution characteristics is useful in determining the environmental security of sources of drinking water. 
Miyun Reservoir is the largest man-made reservoir in North China, and it is considered the only basin with clean water remaining in Beijing [6]. Miyun Reservoir is the terminal water-receiving reservoir of the Middle Route of South-to-North Water Diversion Project (SNWDP), the key national water-conservancy project that is currently under construction in China. The Middle Route is built on and across the North China Plain, was and it was designed to relieve water shortages in the north of the country. The middle line of the water transfer project starts at the Danjiangkou Reservoir, and the water channel is excavated northward via Henan province, Hebei Province, Tianjing and Beijing and ends at Miyun Reservoir. The impoundment began at the end of 2015 in Miyun Reservoir, and storage will be improved from 0.8 billion $\mathrm{m}^{3}$ in 2015 to 2 billion $\mathrm{m}^{3}$ in 2020 [7]. However, the impoundment could significantly alter the hydrology and aquatic ecology of the reservoir. For example, most of the associated reservoir riparian zone belongs to a farmland ecosystem that will be submerged after impoundment. Previously, the farmland ecosystem was under extensive high-intensity agricultural management practices such as the application of chemical and organic fertilizers. The urea and ammonium nitrogen fertilizers were converted into nitrates by nitrifying microorganisms and accumulated in the soil. After water diversion, the accumulated soluble ammonium nitrogen and nitrate nitrogen in the soil will enter the water body. Such changes can create new environments that have been significantly altered chemically, physically and biologically, and which can greatly affect the aquatic microorganisms of reservoir system.

Currently, approximately $70 \%$ of the water supply for the urban residents ( 20 million people) in Beijing is derived from Miyun Reservoir. The water security has received more attention in recent years. To date, only few studies have investigated the water quality and phytoplankton communities in Miyun Reservoir [8], but information about the bacterial community is still lacking. It is important to consider the diversity and structure of the microbial community within a drinking water reservoir when assessing ecosystem functions and human health [9]. Therefore, monitoring and analyzing the spatial-temporal dynamics of bacterioplankton community structure and distribution before water transfer is crucial to better understand how inter-basin water transfer impacts water-receiving reservoir ecosystems. In this study, field samples were collected from April to October 2015.

Molecular microbiology provides several powerful tools for exploring the diversity, composition, function and temporal variations of microbial communities in their unique environments [10]. In this study, our primary focus was to gain an overall understanding of bacterial community diversity and structure in Miyun Reservoir before the impacts of impoundment.

\section{Materials and Methods}

\subsection{Sampling Sites}

Miyun Reservoir, located $100 \mathrm{~km}$ northeast of Beijing $\left(40^{\circ} 30^{\prime} \mathrm{N}, 116^{\circ} 55^{\prime} \mathrm{E}\right)$, is the only surface drinking water storage in Beijing. In total, we collected 156 samples from Miyun Reservoir at seven typical sampling sites (BHB, CHB, CHK, BHK, JG, YL and KZX) in different seasons (April, June, August and October). BHB and CHB are near Bai Dam and Chao Dam, respectively. BHK and CHK are two of main inflow rivers. JG and YL are the northern shallow-water regions. KZX is the center of Miyun Reservoir (Figure 1). Samples were collected from BHB, CHB and KZX sites with different depths (the surface (B), middle (Z) and bottom layers (D)) because these sites were in deeper regions of the reservoir. At the other four sites, we sampled only the surface layer water. Finally, we combined the triplicate samples into one sample for each site, so there were 52 samples for determining water parameters and bacterial diversity. The water samples were transported to the laboratory within $12 \mathrm{~h}$ on ice at $4{ }^{\circ} \mathrm{C}$. At each sampling site, two liters of the collected water was filtered through hydrophilic nuclepore filters $(0.22 \mu \mathrm{m}$, Jingteng Laboratory Equipment Co. Ltd., Tianjin, China) and stored at $-70{ }^{\circ} \mathrm{C}$ until DNA extraction, and one liter was used for water quality test. 


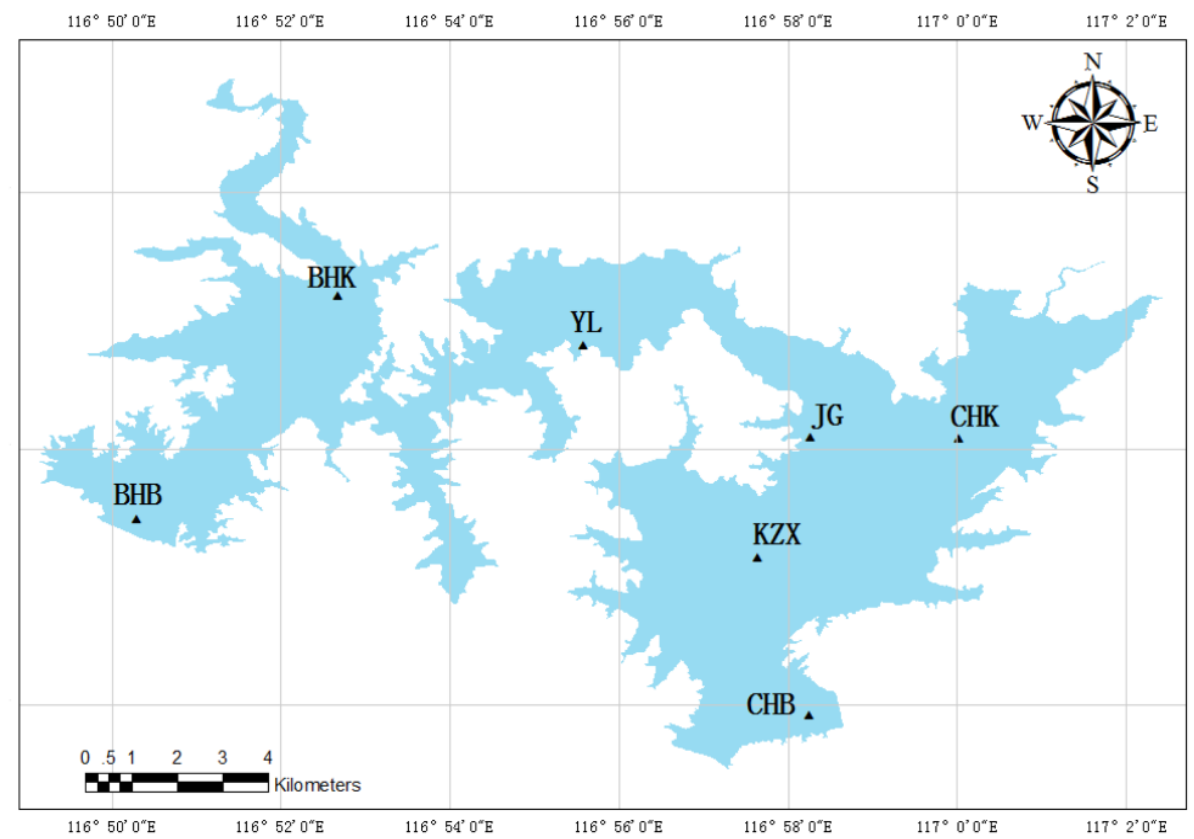

Figure 1. Sampling sites in the Miyun Reservoir. Sampling sites: BHB (Bai River dam area), CHB (Chao River Dam area), KZX (center of the reservoir), BHK (Bai River), CHK (the Chao River), JG (north shallow water area) and YL (north shallow water area). The figure was made by ArcGIS version 10.2.2 (ESRI Company, Redlands, CA, USA).

\subsection{Water Quality Parameters}

The water quality parameters of all water samples were measured (Supplementary Table S1). Temperature (T), dissolved oxygen (DO), and total dissolved solids (TDS) were measured in situ with a water quality analysis instrument (AP-7000, Aquaread Ltd., Broadstairs Kent, UK). The other environmental variables, including total nitrogen (TN), total phosphorus (TP), ammonia $\left(\mathrm{NH}_{4}^{+}\right)$, nitrate $\left(\mathrm{NO}_{3}{ }^{-}\right)$and nitrite $\left(\mathrm{NO}_{2}{ }^{-}\right)$, were taken to laboratory and tested according to the standard methods described in the current National Drinking Water Quality Standard (GB5749-2006).

\subsection{DNA Extraction, PCR Amplification and Illumina HiSeq Sequencing}

The next-generation sequencing technology has immensely contributed to the global increase in microbial diversity and ecology studies employing samples from different environments, for example, water, soil and extreme environments [11-13]. In this study, we applied the next-generation sequencing technology named Illumina HiSeq sequencing to detect bacteria diversity in the reservoir. Microbial DNA was extracted from the water samples using a Water DNA Kit (Omega Bio-Tek, USA) following the manufacturer's protocols. The V3-V4 region of the bacterial $16 \mathrm{~S}$ ribosomal RNA gene was amplified with the primers 338F (5'-barcode-ACTCCTACGGGAGGCAGCA-3') and 806R (5'-ACTCCTACGGGAGGCAGCA-3') by PCR, as previously described [14]. Amplicons were extracted from $2 \%$ agarose gels and purified using the AxyPrep DNA Gel Extraction Kit (Axygen Biosciences, Union City, CA, USA) according to the manufacturer's instructions. Amplicons were quantified using QuantiFluor ${ }^{\mathrm{TM}}$-ST (Promega, Madison, WI, USA). Purified amplicons were pooled in equimolar concentrations and sequenced using 300-base paired-end protocol (PE) on an Illumina HiSeq platform. The raw reads were deposited into the NCBI Sequence Read Archive (SRA) database (Accession Number: SUB3135949). Raw FASTQ files were quality-filtered using QIIME (version 1.17). Operational taxonomy units (OTUs) were clustered with a $97 \%$ similarity cutoff using UPARSE (version 7.1, Tiburon, CA, USA), and chimeric sequences were identified and removed using UCHIME. 
The taxonomy of each 16S rRNA gene sequence was analyzed by the Ribosomal Database Project (RDP) Classifier against the SILVA (SSU115) 16S rRNA database using a confidence threshold of 70\%.

\subsection{Data Analyses}

Normalization is the process of transforming data to remove the confounding effects of different sample sizes [15]. The sequence number of each sample was normalized to 19,380 reads based on the minimum number of valid sequences to ensure initial similar sequencing depths when comparing the diversity indices. In the alpha-diversity analysis, the community richness (Chao 1 and ACE) [16] and diversity (Shannon and Simpson) [17] indices were estimated from the number of OTUs at the 97\% similarity level using MOTHUR [18]. To assess the dissimilarities of temporal and spatial patterns of bacterial community in four seasons, non-metric multidimensional scaling (NMDS) and Kruskal-Wallis rank sum test were performed. Linear discriminant analysis effect size (LEfSe) was used to determine the dominant seasonal biomarkers of the different seasons with an effect size threshold of 2.5 (on a $\log 10$ scale) [19]. A redundancy discriminant analysis (RDA) function in the vegan package in R was utilized to compare the species-environment correlations, and these correlations were assessed with the "envfit" function to determine the significance of the environmental factors. PICRUSt is a technique that predicts metabolic functions from $16 \mathrm{~S}$ community sequences [20]. PICRUSt was used in this study to infer the metabolic and potential functional capabilities of the observed bacterial communities.

\section{Results}

\subsection{A Brief Overview of the Diversity of Bacterioplankton}

The sequencing libraries of the microbial $16 \mathrm{~S}$ rRNA genes yielded 1,471,492 reads after filtering and removing the chimeric sequences from the 1,549,331 raw reads (Table S2.). The average length of the sequences was 439.79 nucleotides with barcode primers trimmed. The dominant length distributions were approximately $421-440$ and $441-460 \mathrm{bp}$.

To assess the sampling completeness, Good's coverage estimator was used and calculated by randomly selecting sequence reads from a given sample. The Good's coverage estimations of the microbial $16 \mathrm{~S}$ rRNA libraries were all over 0.98 , indicating that the libraries accurately reflect the bacterial communities in the samples. The Chao estimator demonstrated community richness. The rarefaction curves (Figure 2) and Chao estimator (Table S2) indicated that the YL_AUG sampling site had the highest richness, while the BHB_B_OCT site had the lowest richness. In addition, the Shannon index (Table S2) was measured to characterize community diversity that ranged from 3.48 to 5.45 , indicating a high level of overall biodiversity. Based on the Shannon index, the YL_AUG site also had the highest microbial biodiversity. 


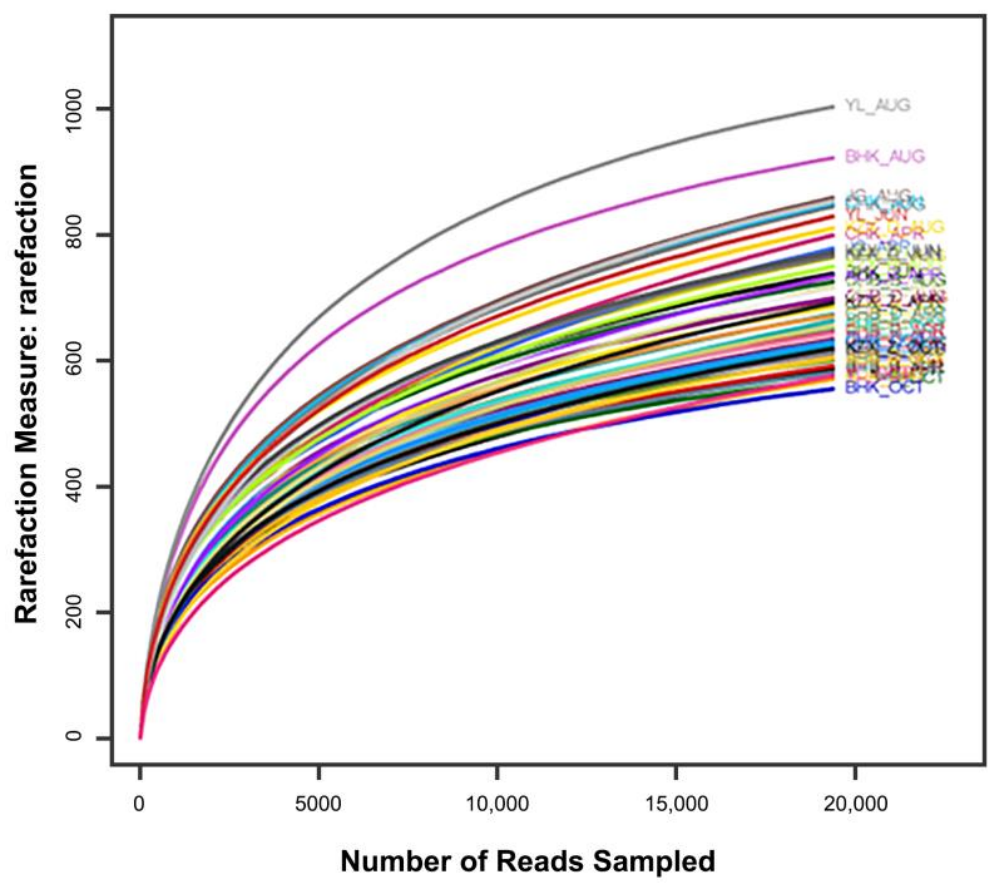

Figure 2. Rarefaction curves for Operational taxonomy units (OTUs) that were calculated using MOTHUR with reads normalized to 19,380 for each sample.

\subsection{Temporal and Spatial Dynamic Patterns}

Non-metric multidimensional scaling (NMDS) was used to determine the temporal and spatial patterns among the samples. The NMDS plot (Figure 3) shows that the samples from the same seasons were strongly clustered. A Kruskal-Wallis test was used to evaluate the differences in the bacterial communities between different sampling sites. The chi-square result of 10.165 and a $p$-value of 0.1179 were found, which indicated that the bacterial communities did not vary significantly between sampling sites. However, the $p$-values of the Kruskal-Wallis test between the four seasons were less than 0.001 (Kruskal-Wallis test chi-squared $=17.02, p$-value $=0.0007001$ ), suggesting that seasonal change was a significant factor in the structure of the microbial communities. The depth influence was also analyzed by comparing samples from the surface, middle and bottom layers. Chi-squared and $p$-value were 0.59963 and 0.741 , respectively, indicated there was no significant variation between different depths. These results indicated that seasonal changes were considerably more influential on the community structure, whereas spatial differences, including depth, had little effect. 


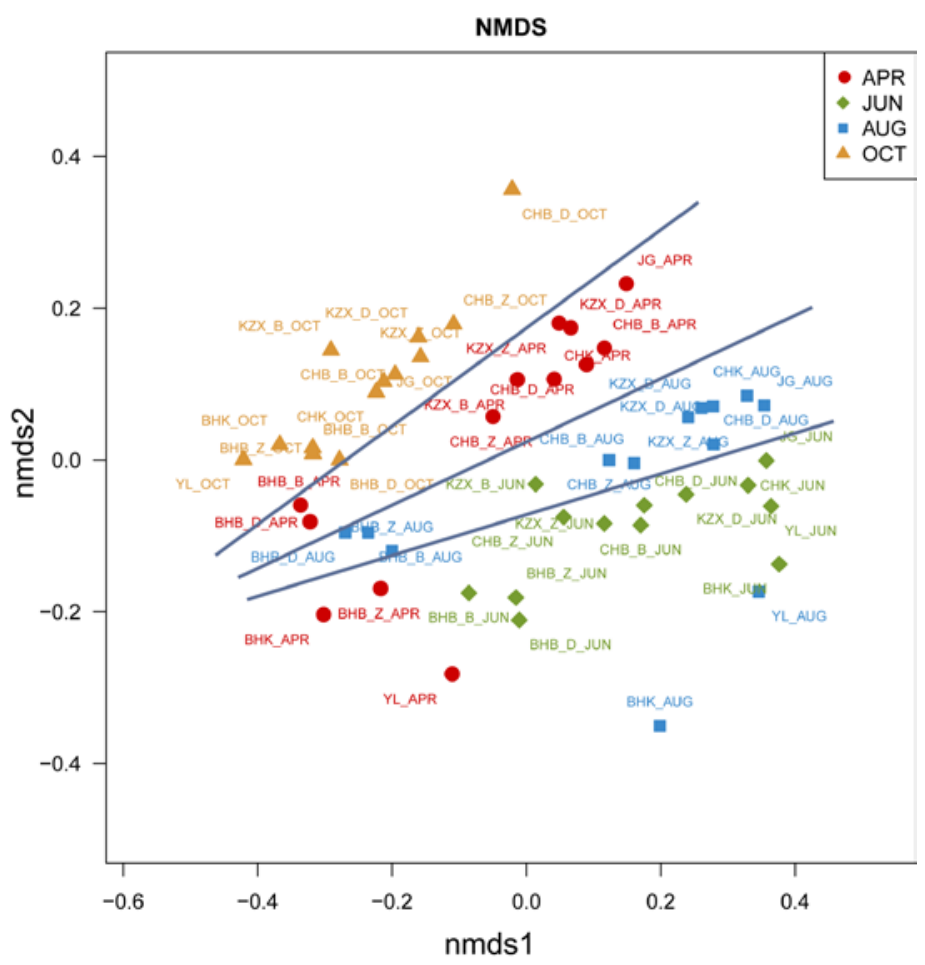

Figure 3. Non-metric multidimensional (NMDS) scaling plot distances used to estimate the temporal and spatial dynamics of the community structure.

\subsection{Community Structure and Seasonal Biomarkers}

Across all samples, 37 phyla, 78 classes, 154 orders, 296 families and 544 genera were identified (Figure 4). The dominant bacteria in all samples were classified in the Firmicutes phylum with an average relative abundance of $23.47 \%$. The next most abundant phyla were Proteobacteria, Cyanobacteria and Bacterioidetes, accounting for $14.42-34.78 \%$, 3.81-36.78\%, and $5.45-25.98 \%$, respectively.

At the genus level, the five most abundant genera were Bacillus, Cyanobacteria_norank, Lactococcus, CL500_3 and CL500_29_marine_group (Figure 5). Bacillus was the most abundant genus in all four seasons with an average percentage of $16.86 \%$, and the highest percentage of Bacillus was reached in Oct (26.292\%). Lactococcus averaged 3.63\% over all seasons. CL500-3 was also abundant in all seasons, and its percentage was highest $(7.6 \%)$ in June.

We also used the LEfSe analysis method to explore the seasonal biomarker species. This method detected 10 different abundant taxa with linear discriminant analysis (LDA) score higher than 2.5 $(p<0.05)$. As shown in Figure 6, Flavobacterium and Limnohabitans were the most abundant genera in April, while Synechococcus and Roseiflexus were enriched in the June samples. Limnobacter were abundant in August and Bacillus, Lactococcus, Pseudomonas, Stenotrophomonas and Oceanobacillus were abundant in October. 


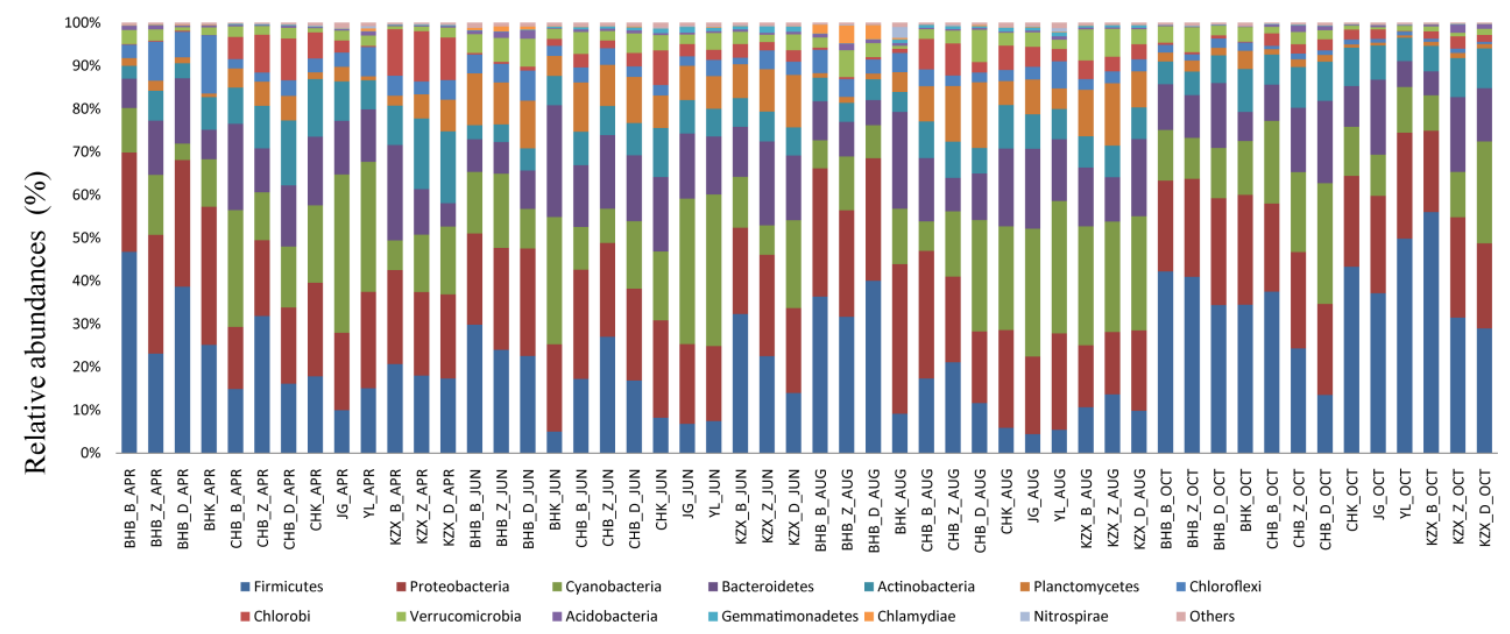

Figure 4. Phylum-level changes of the bacterial sequences in different month-site assemblages.

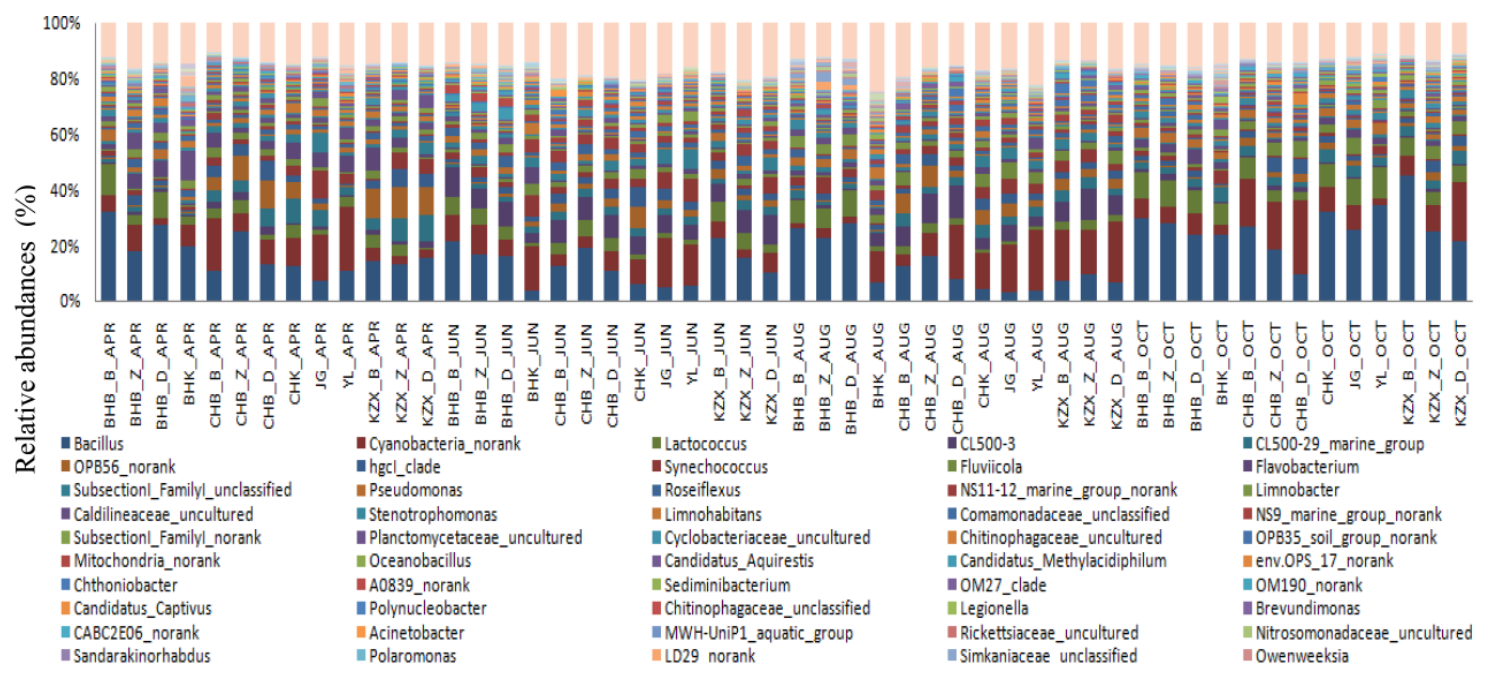

Figure 5. Genus-level changes of the bacterial sequences in different month-site assemblages.

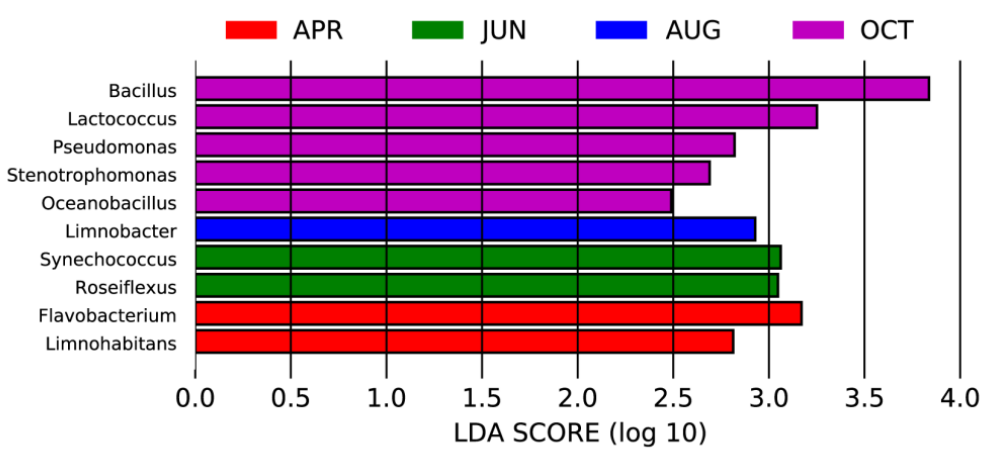

Figure 6. The seasonal biomarkers in the Miyun Reservoir as identified with LEfSe (LDA score > 2.5, $p<0.05)$.

\subsection{Relationship with Environmental Parameters}

The relationships between the genus-level structures (top 15 genera without unclassified taxa) and the water environmental variables were assessed by an RDA (Figure 7) and Mantel test. The first axis explained $21.3 \%$ of the variation in the species-environment interactions, the first and second axes 
together explained 27\%. The Mantel test showed that both temperature and TDS reached $0.001 \mathrm{Pr}$ with 999 permutations, and these variables had strong effects on the microbial community structure. The corresponding values were 0.002 for TP, 0.006 for $\mathrm{DO}$ and 0.012 for $\mathrm{TN}$, and the values for the other parameters were greater than 0.1 . Thus, our findings provide evidence that the seasonal changes in the bacterial community structure were significantly correlated to a combination of temperature, and TDS, TP, DO and TN concentrations.

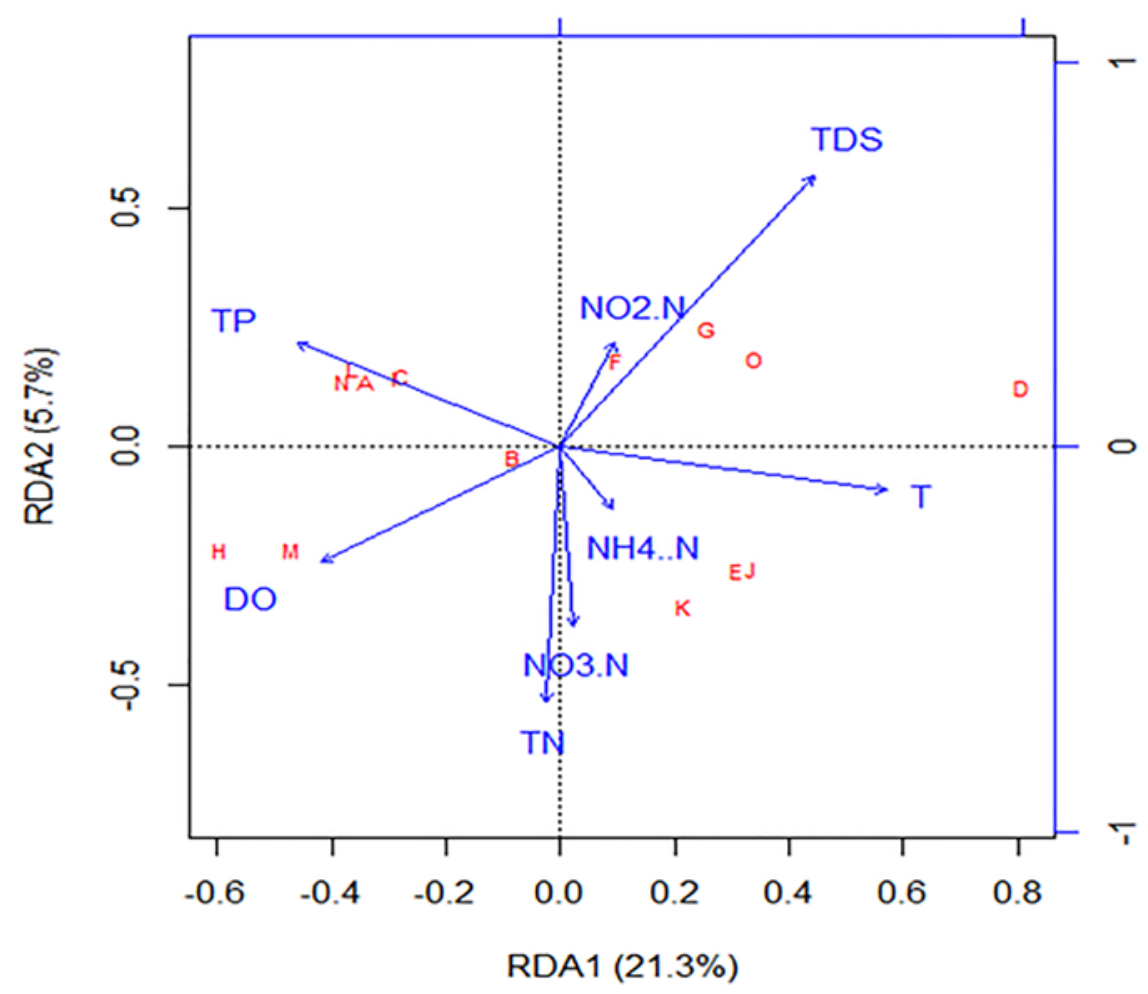

Figure 7. Redundancy analysis (RDA) biplot of the distribution of the dominant bacterial genera with environmental parameters in the Miyun Reservoir. A: Bacillus, B: CL500.29_Marine_group, C: Lactococcus, D: CL500_3, E: Synechococcus, F: hgcI_clade, G: Fluviicola, H: Flavobacterium, I: Pseudomonas, J: Roseiflexus, K: Limnobacter, L: Stenotrophomonas, M: Limnohabitians, N: Oceanobacillus, O: Chthoniobacter. Temperature $(\mathrm{T})$, dissolved oxygen (DO), total dissolved solids (TDS), total nitrogen (TN), total phosphorus (TP), ammonia $\left(\mathrm{NH}^{4+}\right)$, nitrate $\left(\mathrm{NO}^{3-}\right)$ and nitrite $\left(\mathrm{NO}^{2-}\right)$.

\subsection{Potential Functions Diversity}

A broad phylogenetic diversity and identified organisms involved in multiple essential environmental processes, including cellular processes, environmental information processing, genetic information processing and metabolism, were found (Figure 8). The metabolism related to environmental processing is the focus of this paper. The most common membrane transport genes present in environmental information processing were those related to ATP binding cassette $(\mathrm{ABC})$ transporters and two-component systems. In addition, KEGG orthology (KO) is involved in the environmental sensing and biodegradation of xenobiotics such as benzene organic compounds (benzoate, ethylbenzene, nitrotoluene and toluene, etc.) and pesticides (DDT and Atrazine) (Figure S1). 


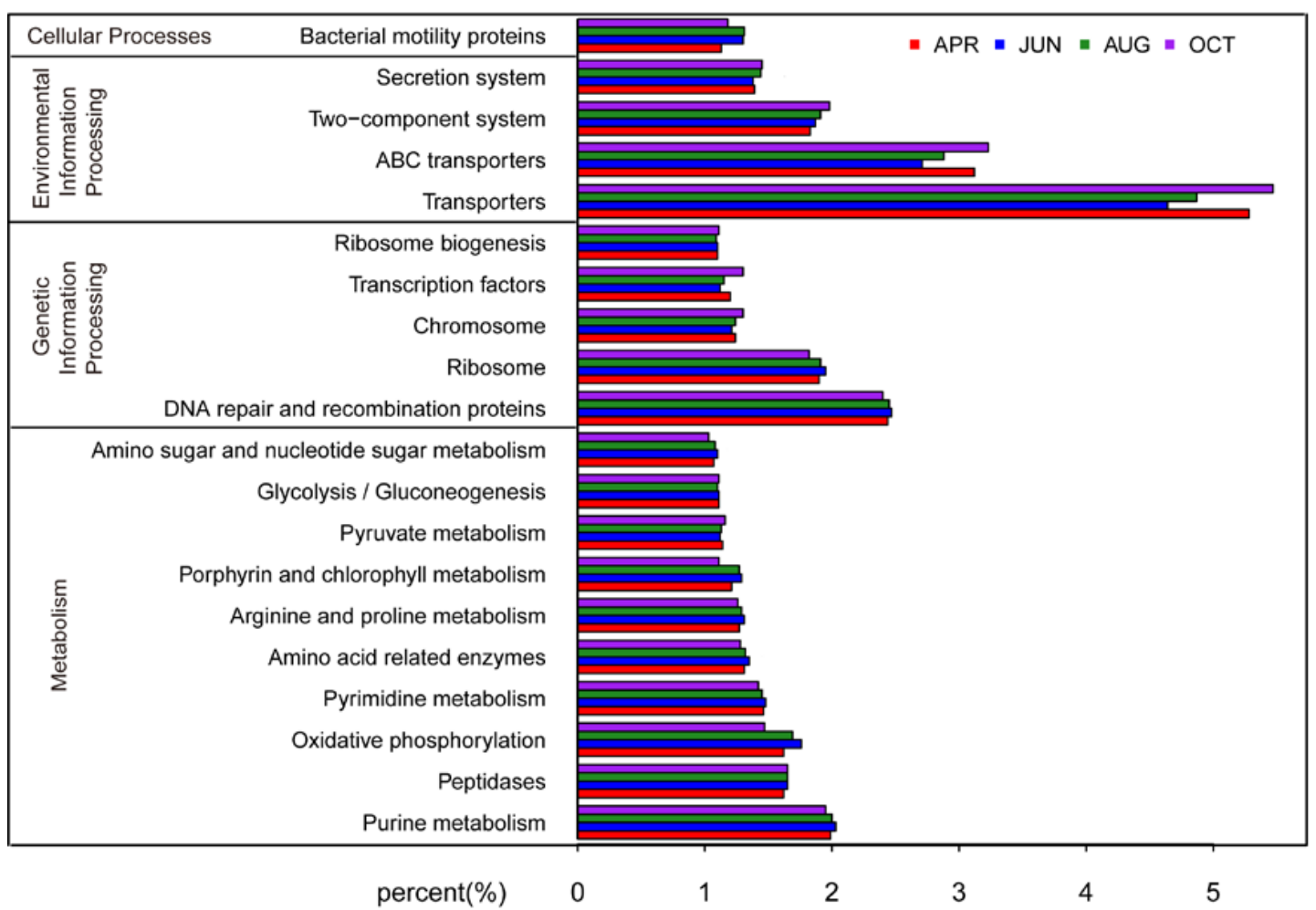

Figure 8. Multiple essential environmental process predictions of the bacterial communities in the Miyun Reservoir using PICRUSt.

\section{Discussion}

China experiences serious water resource shortages and considerable seasonal and regional imbalances in the distribution of water resources [21,22]. The latest National Water Source Report indicated that more than 300 cities have inadequate water supplies, particularly in North China. To alleviate severe drinking water shortages, the Middle Line of the South-to-North Water Diversion will solve the water shortage in North China. However, the effects of water transfers on the bacterioplankton community and other organisms can be interpreted by considering it as a disturbance. Therefore, the study on temporal and spatial dynamics of bacterioplankton throughout the whole year is very important for understanding the diversity, structure and function of the ecosystem for the reservoir before the water transfer.

With recent advances in next-generation sequencing technology, they show insights in terms of microbial diversity, structure and responses to environmental changes [23]. They can allow us to monitor the consequences of the changes in environmental conditions. In this large-scale next-generation sequencing survey, we demonstrated that Miyun Reservoir has a highly complex and dynamic environment. Our results suggested that seasonal changes were considerably more influential on the community structure, and spatial differences, including depth, had little effect (Figure 3). This result may be due to the substantial anthropogenic disturbance in the reservoir that results in mixing across depths and locations, leading to a relatively homogeneous spatial composition of bacteria.

Bacteria are the majority of the food web of the aquatic ecosystem, and play indispensable roles in various biogeochemical processes. They can be useful in assessing the health of the aquatic ecological environment [24]. Our results suggest that there was a complex combination of environmental and biological factors that shaped the structure and distribution of the bacterial community in Miyun Reservoir. Roseiflexus and Synechococcus genera were positively correlated with temperature (Figure 7), and these genera are more enriched as seasonal biomarkers in the summer (Figure 6). This finding 
is consistent with the representatives of these genera that are thermophilic phototrophs, especially in hot spring conditions [25-27]. Some researchers have reported that the abundance and biomass of Synechococcus sp. showed strong seasonal relationships with temperature [28], and this genera provided important sources of organic carbon and nutrients for the summer food web [29]. This is a health concern in some cases, as Synechococcus blooms can produce harmful toxins [30-32]. Thus, we should strengthen the prevention and treatment of Cyanobacteria Synechococcus blooms in warmer seasons. RDA plot (Figure 7) also showed that the genera Flavobacterium and Limnohabitans were positively related with DO. Flavobacterium species are common denitrifying bacteria that have been isolated from various habitats (freshwater, seawater, sediment, soil, etc.) and display a wide variety of physiological characteristics [33]. Compared with conventional denitrifying bacteria, Flavobacterium species can grow well and exhibit denitrification activity under aerobic conditions. Moreover, most of these strains are able to degrade organic matter via heterotrophic nitrification and metabolic activities [34,35]. In the present study, we found that Limnohabitans sp. was abundant in the spring season (Figure 6). In the aquatic ecosystem, the genus Limnohabitans plays a prominent role in carbon flow from algal-derived substrates to the plankton grazer food chain, and contributes substantially to the total bacterial biomass [36]. In our study, the genus Limnohabitans also showed a weak relationship with $\mathrm{TN}$, indicating that this genus may be involved in nitrogen recycling in freshwater environments. Our result is similar to that described by Yan et al. [37]. The most abundant genus Bacillus was associated with TP concentrations. Phosphorus is a key environmental factor with important and unique biogeochemical cycles in aquatic ecosystems, and phosphorus (TP) has been found to be correlated with the structural and functional capability of bacterial and archaeal communities in freshwater ecosystems [38]. In addition, Bacillus spp. was also found to be the dominant form of bacteria that produce phosphates in aquaculture pond systems [39].

The metabolic and potential functional capabilities of the observed bacterioplankton communities were revealed by the PICRUSt technique that accurately provides metabolic insights from metagenome sequences [19]. The most common membrane transport genes present in environmental information processing were those related to ATP binding cassette $(\mathrm{ABC})$ transporters and two-component systems (Figure 8). ABC transporters, which are ubiquitous in bacteria, archaea, eukarya and some giant viruses, provide a variety of transport functions that utilize ATP to hydrolyze energy, drive transport reactions and mediate the uptake of a wide variety of nutrients [40]. The functions of two-component systems enable bacteria to detect physical and chemical changes, and this information is transferred to the bacterial nucleus via the cytoplasm, where gene expression is regulated [41]. To gain further insights into the metabolism of aromatic hydrocarbon compounds, we inspected the abundance of transcripts related to the degradation of these compounds. Interestingly, during functional categorization of the transcripts, those encoding enzymes of the major pathways were observed to be involved in the degradation of xenobiotics such as benzene organic compounds (benzoate, ethylbenzene, nitrotoluene and toluene, etc.) and pesticides (DDT and atrazine) (Figure S1)). Currently, water sources in China contain various xenobiotic pollutants from industrial discharge and agricultural pesticides. These pollutants may consist of persistent organic pollutants (POPs) such as DDT, polychlorinated biphenyls (PCB), and dioxins. These POPs have greatly affected the soil, air and aquatic environment qualities and even human health [42-44]. The Chao River and Bai River are the main water inflows of the Miyun Reservoir. The catchments of these rivers are mostly covered by agricultural and residential land, which are heavily impacted by human activities. A recent report showed that the major polychlorinated biphenyls (PCBs) and organochlorine pesticides (OCP) contaminant in the surface water around Beijing were hexachlorocyclohexanes (HCHs), endosulfan, DDTs and HCB dominated by di-CBs, tri-CBs, tetra-CBs and penta-CBs [45]. Yu et al. [46] also reported that hexachlorocyclohexanes (HCHs) and hexachlorobenzene (HCB) were the dominant types of OCPs in this region, and PCB-118 was the major component of the PCBs in both water and soil samples. Some reports have proven that a diverse group of bacteria, such as Acinetobacter, Bacillus, Flavobacterium and Pseudomonas, have the ability to biodegrade certain PCBs and OCPs $[47,48]$. Therefore, the relation between bacterial 
functional gene metabolism and the biodegradation of organic pollutants suggested that microbial communities actively may maintain the water quality in the Miyun Reservoir. Monitoring of POPs and control measures should be implemented to further reduce the pollution in this region in the future study.

The impact of the SNWDP on the aquatic environment is complex due to human regulations and disturbances. Because assessing the impacts of water diversion is a long-term project, data collected before water transfer are crucial to better understanding how inter-basin water transfer impacts water-receiving reservoir ecosystems. In this study, our results showed that Firmicutes, Proteobacteria, Cyanobacteria and Bacterioidetes were the major phyla in the water column before water diversion. According to our recent preliminary investigation, the Proteobacteria, Cyanobacteria, Actinobacteria, Bacteroidetes and Verrucomicrobia were the dominant phyla after water transfer. The relative abundance of the Proteobacteria and Verrucomicrobia increased significantly $(p<0.05)$ (data not shown). Moreover, the ecological niche of the genera Candidatus Methylacidiphilum, Chitinophagaceae and OM27 clade were significantly differentiated $(p<0.05)$, and interspecies niche competition becomes more intense after the water transfer. Therefore, water diversion projects make the local habitat environment change. These changes definitely change the reservoir aquatic environment.

Supplementary Materials: The following are available online at http:/ / www.mdpi.com/2073-4441/10/6/709/s1. Table S1 Water quality analysis of samples collected from the Miyun Reservoir. Table S2 Richness and diversity indices used in this study. Figure S1 KEGG orthology $(\mathrm{KO})$ involved in environmental sensing and xenobiotic biodegradation in Miyun Reservoir.

Author Contributions: J.Q. and C.J. conceived the idea. Q.Z. designed the experiments; Q.L., J.Q., Z.L., M.Z., H.Z., W.L., P.L. and M.Y. conducted the experiments. J.Q. analyzed the data and wrote the manuscript. All authors discussed the results, reviewed and approved the final manuscript.

Funding: This research was financially supported by the Beijing Natural Science Foundation (5162007, J150003), the Beijing Science \& Technology Plan (D151100005915003), the Beijing Nova program (Z161100004916084), and the Beijing Young Scholar Project (2015000020060G146).

Acknowledgments: The authors are grateful for the support from these programs. We thank anonymous reviewers and Xuming Wang (Beijing Academy of Agriculture and Forestry Sciences) and Terence L. Marsh (Michigan State University) for their useful comments in improving this manuscript.

Conflicts of Interest: The authors declare no competing financial interests.

\section{References}

1. Nogueira, M.G.; Henry, R.; Maricatto, F.E. Spatial and temporal heterogeneity in the Jurumirim Reservoir, São Paulo, Brazil. Lakes Reserv. Res. Manag. 1999, 4, 107-120. [CrossRef]

2. Shen, H.; Li, B.; Cai, Q.; Han, Q.; Gu, Y.; Qu, Y. Phytoplankton functional groups in a high spatial heterogeneity subtropical reservoir in China. J. Gt. Lakes Res. 2014, 40, 859-869. [CrossRef]

3. Silva, L.H.S.; Huszar, V.L.M.; Marinho, M.M.; Rangel, L.M.; Brasil, J.; Domingues, C.D.; Branco, C.C.; Roland, F. Drivers of phytoplankton, bacterioplankton, and zooplankton carbon biomass in tropical hydroelectric reservoirs. Limnol. Ecol. Manag. Inland Waters 2014, 48, 1-10. [CrossRef]

4. Li, Z.; Lu, L.; Guo, J.; Yang, J.; Zhang, J.; He, B.; Xu, L. Responses of spatial-temporal dynamics of bacterioplankton community to large-scale reservoir operation: A case study in the Three Gorges Reservoir, China. Sci. Rep. 2017, 7, 42469. [CrossRef] [PubMed]

5. Macnaughton, C.J.; McLaughlin, F.; Bourque, G.; Senay, C.; Lanthier, G.; Harvey-Lavoie, S.; Legendre, P.; Lapointe, M.; Boisclair, D. The Effects of Regional Hydrologic Alteration on Fish Community Structure in Regulated Rivers. River Res. Appl. 2017, 33, 249-257. [CrossRef]

6. Ma, H.; Yang, D.; Tan, S.K.; Gao, B.; Hu, Q. Impact of climate variability and human activity on stream flow decrease in the Miyun Reservoir catchment. J. Hydrol. 2010, 389, 317-324. [CrossRef]

7. Beijing National South-to-North Water Division Office. Available online: http://www.bjnsbd.gov.cn/ (accessed on 15 May 2018).

8. Su, M.; Yu, J.; Pan, S.; An, W.; Yang, M. Spatial and temporal variations of two cyanobacteria in the mesotrophic Miyun reservoir, China. J. Environ. Sci. 2014, 26, 289-298. [CrossRef] 
9. Rossum, T.V.; Peabody, M.A.; Uyaguari-Diaz, M.I.; Cronin, K.I.; Chan, M.; Slobodan, J.R.; Nesbitt, M.J.; Suttle, C.A.; Hsiao, W.W.L.; Tang, P.K.C. Year-Long Metagenomic Study of River Microbiomes across Land Use and Water Quality. Front. Microbiol. 2015, 6, 1405. [CrossRef] [PubMed]

10. Wang, D.-Z.; Kong, L.-F.; Li, Y.-Y.; Xie, Z.-X. Environmental Microbial Community Proteomics: Status, Challenges and Perspectives. Int. J. Mol. Sci. 2016, 17, 1275. [CrossRef] [PubMed]

11. Debroas, D.; Domaizon, I.; Humbert, J.F.; Jardillier, L.; Lepère, C.; Oudart, A.; Taib, N. Overview of freshwater microbial eukaryotes diversity: A first analysis of publicly available metabarcoding data. FEMS Microbiol. Ecol. 2017, 93. [CrossRef] [PubMed]

12. Žifčáková, L.; Větrovský, T.; Howe, A.; Baldrian, P. Microbial activity in forest soil reflects the changes in ecosystem properties between summer and winter. Environ. Microbiol. 2016, 18, 288-301. [CrossRef] [PubMed]

13. Fernandez, L.; Mercader, J.M.; Planas-Fèlix, M.; Torrents, D. Adaptation to environmental factors shapes the organization of regulatory regions in microbial communities. BMC Genom. 2014, 15, 877. [CrossRef] [PubMed]

14. Anahtar, M.N.; Bowman, B.A.; Kwon, D.S. Efficient Nucleic Acid Extraction and 16S rRNA Gene Sequencing for Bacterial Community Characterization. J. Vis. Exp. JoVE 2016. [CrossRef] [PubMed]

15. Lagkouvardos, I.; Fischer, S.; Kumar, N.; Clavel, T. Rhea: A transparent and modular R pipeline for microbial profiling based on 16S rRNA gene amplicons. PeerJ 2017, 5. [CrossRef] [PubMed]

16. Chao, A. Nonparametric estimation of the numbers of classes in a population. Scand. J. Stat. 1984, 11, 265-270. [CrossRef]

17. Shannon, C.E. A Mathematical Theory of Communication. SIGMOBILE Mob. Comput. Commun. Rev. 2001, 5, 3-55. [CrossRef]

18. Schloss, P.D.; Westcott, S.L.; Ryabin, T.; Hall, J.R.; Hartmann, M.; Hollister, E.B.; Lesniewski, R.A.; Oakley, B.B.; Parks, D.H.; Robinson, C.J. Introducing mothur: Open-source, platform-independent, community-supported software for describing and comparing microbial communities. Appl. Environ. Microbiol. 2009, 75, 7537-7541. [CrossRef] [PubMed]

19. Segata, N.; Izard, J.; Waldron, L.; Gevers, D.; Miropolsky, L.; Garrett, W.S.; Huttenhower, C. Metagenomic biomarker discovery and explanation. Genome Biol. 2011, 12, R60. [CrossRef] [PubMed]

20. Langille, M.G.I.; Zaneveld, J.; Caporaso, J.G.; McDonald, D.; Knights, D.; Reyes, J.A.; Clemente, J.C.; Burkepile, D.E.; Vega Thurber, R.L.; Knight, R.; et al. Predictive functional profiling of microbial communities using $16 \mathrm{~S}$ rRNA marker gene sequences. Nat. Biotechnol. 2013, 31, 814-821. [CrossRef] [PubMed]

21. Varis, O.; Vakkilainen, P. China's 8 challenges to water resources management in the first quarter of the 21st Century. Geomorphology 2001, 41, 93-104. [CrossRef]

22. Jiang, Y. China's water security: Current status, emerging challenges and future prospects. Environ. Sci. Policy 2015, 54, 106-125. [CrossRef]

23. Chu, Z.R.; Wang, K.; Li, X.K.; Zhu, M.T.; Yang, L.; Zhang, J. Microbial characterization of aggregates within a one-stage nitritation-anammox system using high-throughput amplicon sequencing. Chem. Eng. J. 2015, 262, 41-48. [CrossRef]

24. Milan, M.; Carraro, L.; Fariselli, P.; Martino, M.E.; Cavalieri, D.; Vitali, F.; Boffo, L.; Patarnello, T.; Bargelloni, L.; Cardazzo, B. Microbiota and environmental stress: How pollution affects microbial communities in Manila clams. Aquat. Toxicol. 2018, 194, 195-207. [CrossRef] [PubMed]

25. Staff, T.P.O. Correction: Control of Temperature on Microbial Community Structure in Hot Springs of the Tibetan Plateau. PLoS ONE 2013, 8, e62901.

26. Weltzer, M.L.; Miller, S.R. Ecological divergence of a novel group of Chloroflexus strains along a geothermal gradient. Appl. Environ. Microbiol. 2013, 79, 1353-1358. [CrossRef] [PubMed]

27. Ward, D.M.; Castenholz, R.W.; Miller, S.R. Cyanobacteria in Geothermal Habitats. In Ecology of Cyanobacteria II; Springer: Dordrecht, The Netherlands, 2012; pp. 39-63. ISBN 978-94-007-3854-6.

28. Xia, X.; Vidyarathna, N.K.; Palenik, B.; Lee, P.; Liu, H. Comparison of the Seasonal Variations of Synechococcus Assemblage Structures in Estuarine Waters and Coastal Waters of Hong Kong. Appl. Environ. Microbiol. 2015, 81, 7644-7655. [CrossRef] [PubMed]

29. Moisan, T.A.; Blattner, K.L.; Makinen, C.P. Influences of temperature and nutrients on Synechococcus abundance and biomass in the southern Mid-Atlantic Bight. Cont. Shelf Res. 2010, 30, 1275-1282. [CrossRef] 
30. Phlips, E.J.; Badylak, S.; Lynch, T.C. Blooms of the picoplanktonic cyanobacterium Synechococcus in Florida Bay, a subtropical inner-shelf lagoon. Limnol. Oceanogr. 1999, 44, 1166-1175. [CrossRef]

31. Jakubowska, N. Toxic Picoplanktonic Cyanobacteria-Review. Mar. Drugs 2015, 13, 1497-1518. [CrossRef] [PubMed]

32. Teneva, I.; Mladenov, R.; Belkinova, D.; Dimitrova-Dyulgerova, I.; Dzhambazov, B. Phytoplankton community of the drinking water supply reservoir Borovitsa (South Bulgaria) with an emphasis on cyanotoxins and water quality. Cent. Eur. J. Biol. 2010, 5, 231-239. [CrossRef]

33. Bernardet, J.-F.; Bowman, J.P. The Genus Flavobacterium. In The Prokaryotes; Springer: New York, NY, USA, 2006; pp. 481-531. ISBN 978-0-387-25497-5.

34. Zhang, S.; Pang, S.; Wang, P.; Wang, C.; Guo, C.; Addo, F.G.; Li, Y. Responses of bacterial community structure and denitrifying bacteria in biofilm to submerged macrophytes and nitrate. Sci. Rep. 2016, 6, 36178. [CrossRef] [PubMed]

35. Chen, J.; Han, Y.; Wang, Y.; Gong, B.; Zhou, J.; Qing, X. Start-up and microbial communities of a simultaneous nitrogen removal system for high salinity and high nitrogen organic wastewater via heterotrophic nitrification. Bioresour. Technol. 2016, 216, 196-202. [CrossRef] [PubMed]

36. Kasalický, V.; Jezbera, J.; Hahn, M.W.; Šimek, K. The Diversity of the Limnohabitans Genus, an Important Group of Freshwater Bacterioplankton, by Characterization of 35 Isolated Strains. PLoS ONE 2013, 8, e58209. [CrossRef] [PubMed]

37. Yan, Q.; Bi, Y.; Deng, Y.; He, Z.; Wu, L.; Nostrand, J.D.V.; Shi, Z.; Li, J.; Wang, X.; Hu, Z.; et al. Impacts of the Three Gorges Dam on microbial structure and potential function. Sci. Rep. 2015, 5, 8605. [CrossRef] [PubMed]

38. Lebrun, E.S.; King, R.S.; Back, J.A.; Kang, S. Microbial Community Structure and Function Decoupling Across a Phosphorus Gradient in Streams. Microb. Ecol. 2017, 75, 1-10. [CrossRef] [PubMed]

39. Barik, S.K.; Purushothaman, C.S.; Mohanty, A.N. Phosphatase activity with reference to bacteria and phosphorus in tropical freshwater aquaculture pond systems. Aquac. Res. 2015, 32, 819-832. [CrossRef]

40. Pohl, A.; Devaux, P.F.; Herrmann, A. Function of prokaryotic and eukaryotic ABC proteins in lipid transport. Biochim. Biophys. Acta BBA Mol. Cell Biol. Lipids 2005, 1733, 29-52. [CrossRef] [PubMed]

41. Igoshin, O.A.; Alves, R.; Savageau, M.A. Hysteretic and graded responses in bacterial two-component signal transduction. Mol. Microbiol. 2008, 68, 1196-1215. [CrossRef] [PubMed]

42. Fu, J.; Mai, B.; Sheng, G.; Zhang, G.; Wang, X.; Peng, P.; Xiao, X.; Ran, R.; Cheng, F.; Peng, X.; et al. Persistent organic pollutants in environment of the Pearl River Delta, China: An overview. Chemosphere 2003, 52, 1411-1422. [CrossRef]

43. Bao, L.J.; Maruya, K.A.; Snyder, S.A.; Zeng, E.Y. China's water pollution by persistent organic pollutants. Environ. Pollut. 2012, 163, 100-108. [CrossRef] [PubMed]

44. Cui, S.; Fu, Q.; Li, Y.-F.; Ma, J.; Tian, C.; Liu, L.; Zhang, L. Modeling the air-soil exchange, secondary emissions and residues in soil of polychlorinated biphenyls in China. Sci. Rep. 2017, 7, 221. [CrossRef] [PubMed]

45. Shao, Y.; Han, S.; Ouyang, J.; Yang, G.; Liu, W.; Ma, L.; Luo, M.; Xu, D. Organochlorine pesticides and polychlorinated biphenyls in surface water around Beijing. Environ. Sci. Pollut. Res. 2016, 23, 24824-24833. [CrossRef] [PubMed]

46. Yu, Y.; Li, Y.; Shen, Z.; Yang, Z.; Mo, L.; Kong, Y.; Lou, I. Occurrence and possible sources of organochlorine pesticides (OCPs) and polychlorinated biphenyls (PCBs) along the Chao River, China. Chemosphere 2014, 114, 136-143. [CrossRef] [PubMed]

47. Shuai, J.; Yu, X.; Zhang, J.; Xiong, A.; Xiong, F. Regional analysis of potential polychlorinated biphenyl degrading bacterial strains from China. Braz. J. Microbiol. 2016, 47, 536-541. [CrossRef] [PubMed]

48. Parte, S.G.; Mohekar, A.D.; Kharat, A.S. Microbial degradation of pesticide: A review. Afr. J. Microbiol. Res. 2017, 11, 992-1012. [CrossRef]

(C) 2018 by the authors. Licensee MDPI, Basel, Switzerland. This article is an open access article distributed under the terms and conditions of the Creative Commons Attribution (CC BY) license (http:/ / creativecommons.org/licenses/by/4.0/). 